\title{
Jornada do produtor: relato de criação de produções audiovisuais para EAD utilizando
} o Design Thinking

\author{
Juliana Fontes \\ juliannafontes@gmail.com
}

Resumo: O trabalho traz um relato de experiência de produções audiovisuais para duas universidades distintas que atuam no ramo EAD no Brasil. O resultado dessas práticas visa contribuir com a geração de ideias e criação de produtos para atender às diferentes necessidades de cada instituição. As produções basearam-se no método do design thinking para mapear e descrever a produção da equipe envolvida, que contou com a participação de profissionais de diversas áreas na produção. Para isso, foi utilizada uma das ferramentas do design thinking, chamada de jornada do usuário, a qual é chamada aqui de jornada do produtor, por narrar não a visão do usuário (os estudantes que irão assistir as videoaulas), e sim a visão dos produtores que conceberam o produto.

Palavras-chave: design thinking, produtos audiovisuais, EAD, jornada do usuário.

\section{Introdução}

O trabalho é um relato de experiência de produções audiovisuais (videoaulas) de uma organização que produz materiais para $\mathrm{EAD}$, das quais a autora desse trabalho integra o quadro de funcionários. A empresa é voltada apenas para realização e execução de materiais de educação a distância para grandes universidades que atuam nessa modalidade no Brasil. As produções basearam-se no método do design thinking, contando com a participação de diversos profissionais, entre eles: designers, designers instrucionais, jornalistas, analistas educacionais, pedagogos, administradores, ilustradores, editores de vídeo e animadores. O relato da produção espera contribuir com a área a partir da geração de ideias e a descrição dos processos produtivos, considerando a criatividade e as estratégias utilizadas como inspiração para outras empresas e produtos do setor no país.

Para mapear e descrever a produção, utilizamos a ferramenta do design thinking chamada de jornada do usuário, que como já informado chamamos aqui de jornada do produtor, por narrar não a visão do usuário, no caso os estudantes que irão assistir as videoaulas, e sim a visão dos produtores que conceberam o produto, explorando todo o seu processo. Por isso, o relato foca no processo de produção audiovisual EAD, tendo como problema de pesquisa a utilização do design thinking no processo de concepção de conteúdos EAD. 


\section{Cor:I:

O Corpus da pesquisa está limitado às duas produções desenvolvidas para duas Universidades EAD do Brasil, denominadas de INSTITUIÇÃO 01 (i01) e INSTITUIÇÃO 02 (i02), a primeira atua com suas disciplinas na modalidade $100 \%$ EAD, enquanto que a segunda tem um público 50\% EAD e o restante 50\% na modalidade presencial. Essas características são fundamentais para entender as particularidades dos produtos escolhidos para cada universidade. Por isso, nos resultados descrevemos o processo de produção dos produtos (protótipos) gerados a partir do entendimento da demanda do cliente/aluno.

\section{Por que produções audiovisuais para atender a demanda do cliente?}

Ao perceber as potencialidades dos meios audiovisuais e encarando o vídeo como um meio de massa, é justamente nesse cenário que essas produções despertam um interesse central na pesquisa. Primeiramente, porque esse meio de comunicação tem grande potencial de abrangência no cenário nacional e propicia estabelecer laços sociais e identificações entre seus telespectadores, algo fundamental buscado na educação a distância.

No cenário de EAD há sempre a necessidade por constantes inovações de suas linguagens e ferramentas para o ensino. Com a grande difusão das redes sociais e plataformas multimídia, como o youtube e afins, o vídeo vem ganhando cada vez mais destaque como mídia utilizada dentro das universidades. Isso porque ele pode remeter à ideia do professor em sala de aula e ir muito além disso, estimula por meio do recurso visual imagético à ludicidade, favorecendo a possibilidade de trabalhar as temáticas das mais diversas formas com o intuito de uma complementação pedagógica no processo de ensino-aprendizagem.

Por isso que, ao remeter as produções das duas Universidades (i01 e i02), a equipe de produção considerou colocar o vídeo dentro da proposta pedagógica para ambas as instituições, já que essa mídia é uma tendência cada vez mais forte nesse meio e vem conquistando cada vez mais adeptos em suas produções.

Como nesse contexto há uma necessidade constante da reinvenção das linguagens, foi possível observar que as produções audiovisuais manifestam em sua estrutura uma variedade de composições e mecanismos expressivos para composição de sua mensagem. Essa disposição torna o estudo mais interessante, pois o exercício de práticas que utilizam linguagens diferenciadas/inovadoras atuam numa instância importante para atender a demanda do usuário ao considerar a necessidade do público de cada universidade, fato este determinante a ser considerado pelo método do design thinking e abordado ao narrar a jornada do produtor.

\section{$\Rightarrow$ VIA QEeC}




\section{Implementando o design thinking nas produções}

Durante toda a produção das videoaulas para as duas universidades (i01 a i02), foi utilizado o método do design thinking para realizar os protótipos. De um modo geral, pode-se compreender que o Design thinking, entre outras definições, cabe como um método, uma metodologia para solução de problemas (BROWN, 2010; VIANNA et al., 2012).

Como ele permite o levantamento e reconhecimento das problemáticas durante todo o processo de produção, é possível verificar com clareza os problemas e já considerar possibilidades para resolução dos mesmos, uma vez que as propostas de soluções derivadas do problema devem se encaixar a ele (VIANNA et al., 2012). Além disso, o método permite a aquisição considerável de informações e dados úteis, fornecendo um panorama geral dos acontecimentos.

Como a equipe que trabalhou nos protótipos era plural, desde o início o produto final foi pensando sob diversos olhares pelos funcionários envolvidos da empresa, visando contribuir com ideias e propostas criativas e eficazes. Brown (2010) coloca três pontos como principais elementos para uma boa trajetória no Design Thinking, que são: o compartilhamento de ideias, a experimentação e a empatia (tanto entre a empresa e o designer/produtor quanto com o cliente). Isso se justifica principalmente porque essa metodologia é colaborativa, permite experimentações com protótipos e busca considerar os diferentes olhares da produção "se colocado no lugar do outro", do próprio usuário inclusive, para prever suas necessidades justamente por meio da empatia. Esse último elemento em particular foi bem importante para as produções, pois ele instiga o produtor a sempre lembrar que o Design thinking é pensado por pessoas para resolver problemas de outras pessoas.

Ao consideramos as três etapas do Design Thinking propostas por Brown (2010), conseguimos ver claramente a estrutura de produção que norteou os trabalhos para o desenvolvimento dos vídeos protótipos para as universidades. Vejamos abaixo o mind map do processo: 
Figura 01 - Mind map

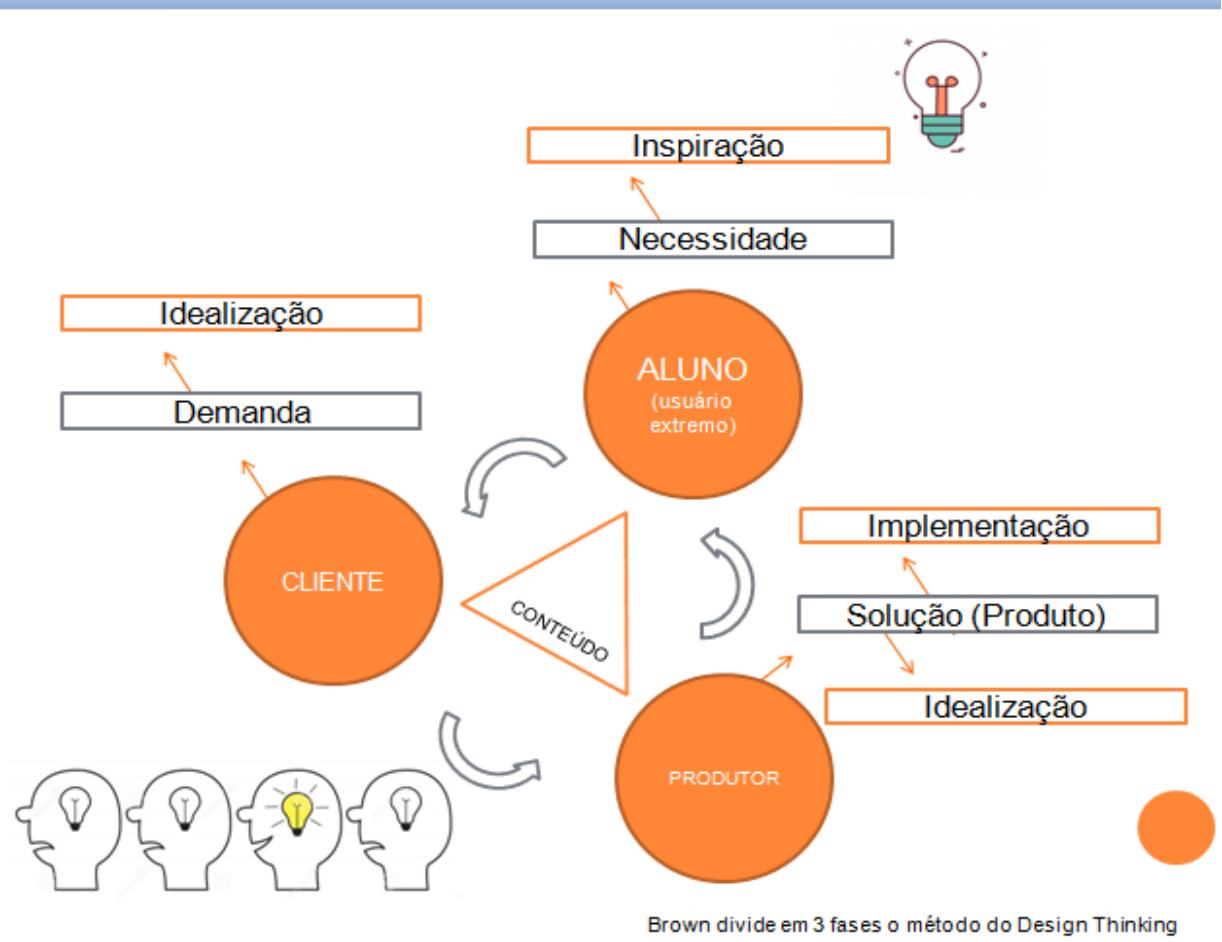

Fonte: Produzida pela autora (2019).

Tudo começa com o aluno, que tem a necessidade de receber o conteúdo das universidades, e nesse caso isso serviria como inspiração, o primeiro gatilho do fluxo. Depois, surgem as demandas que são geradas pelas universidades (que aqui atuam como clientes da empresa que produzirá os materiais), e então temos a segunda etapa do design thinking que é a idealização.

Essa etapa também se estende ao produtor e permeia a outra etapa, que é a implementação do protótipo, ou seja, em conjunto com as demais etapas e atores, o produtor tem a capacidade de propor a solução para a necessidade da demanda, ou seja, o produto. Vale ressaltar que esse processo é cíclico e compartilhado entre as três instâncias e etapas que permeiam a produção. No próximo tópico, são descritos os detalhes até chegar ao produto com mais profundidade, norteados pela ferramenta jornada do usuário (produtor).

\section{A jornada do produtor para produção de videoaulas}

A jornada do usuário, aqui adaptada para jornada do produtor, narra as ações para criações dos protótipos, descrevendo os problemas enfrentados e como foram solucionados antes, durante e depois de sua produção. É nesse momento que a equipe interdisciplinar, após

\section{$=$ VIN SECG}


algumas reuniões, pôde verificar a necessidade dos alunos e compreender a demanda de cada instituição.

Logo, a primeira ação é identificar quais disciplinas (conteúdos) serão trabalhados. Durante esse processo, é proposto o projeto pedagógico para ambas as universidades, nele são contemplados quais mídias serão utilizadas, gerando os objetivos de aprendizagem que vão nortear futuramente o conteúdo que cada entregável (e-book, games, QUIZ, vídeo e etc.) vai abordar (vide primeira linha do quadro abaixo na horizontal).

Figura 02 - Quadro da jornada do produtor

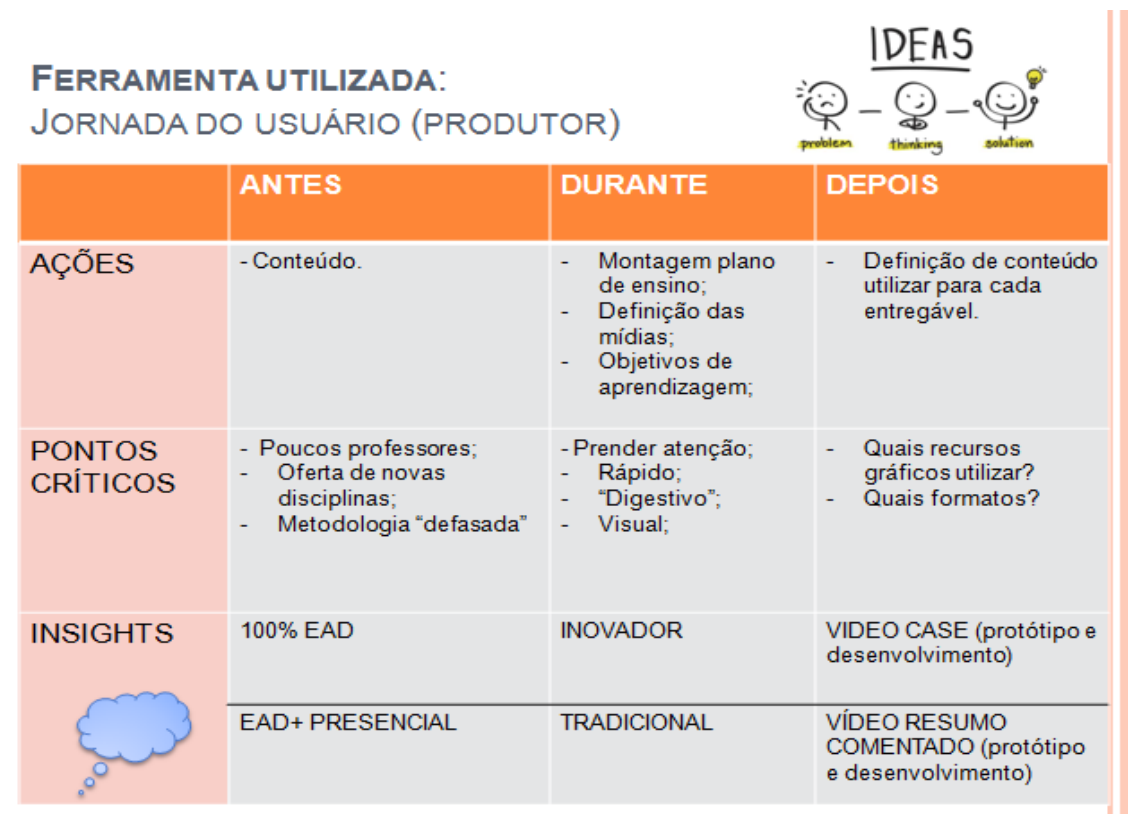

Fonte: Produzida pela autora (2019).

\section{Resultados}

Entende-se que como principal resultado, além da geração de novas ideias, é a proposição de soluções em produtos para o setor. Se focarmos nos pontos práticos, que de certa forma pressupõem a demanda, surge o seguinte questionamento: por qual motivo as universidades precisam terceirizar seus conteúdos?

O motivo é similar para as duas instituições (i01 e i02). Geralmente, essa demanda pode surgir por conta do quadro funcional (limitado ou em escalas) atuantes em ambas as universidades, ou a crescente de turmas, ou por novas disciplinas sendo propostas. Além disso, algo muito importante que gera a demanda de produção e, é um ponto chave para pensar nos protótipos, é a questão dessas universidades trabalharem com algumas metodologias e ferramentas que poderiam ser melhoradas e modernizadas, ou seja, elas buscam inovação em

\section{-2: VIA SEGC}


seus produtos. Diante desses fatores, surgem as demandas por parte das universidades para contratação de produções que trabalhem seu conteúdo de forma diferenciada. Acompanhando as principais tendências do ensino, seria algo que possa "prender" a atenção e ser "digestivo" para seus alunos (vide segunda linha na horizontal do quadro acima). Isso gera um problema a ser resolvido pela equipe de produção de videoaulas da empresa contratada pelas universidades: qual formato de vídeo utilizar? Quais recursos devem estar presentes? Como isso atenderia a demanda do cliente e corresponderia à necessidade dos alunos?

É nesse momento que surgem os insights após toda essa trajetória dos produtores, na qual foi possível propor dois produtos diferentes. Isso se deve claro, diretamente à natureza do ensino de cada universidade, a i01 é $100 \%$ EAD, enquanto que a i02 é 50\% EAD e 50\% presencial. A primeira queria algo mais moderno, clean e com a utilização de recursos gráficos em seus vídeos. A segunda, por manter parte de seu público de forma presencial, também utilizaria os entregáveis dentro da sala aula em momentos específicos e programados e, por conta disso, queria algo que realmente fosse mais conservador e formal, simulando a figura do professor.

Figura 03 - Modelo das videoaulas produzidas

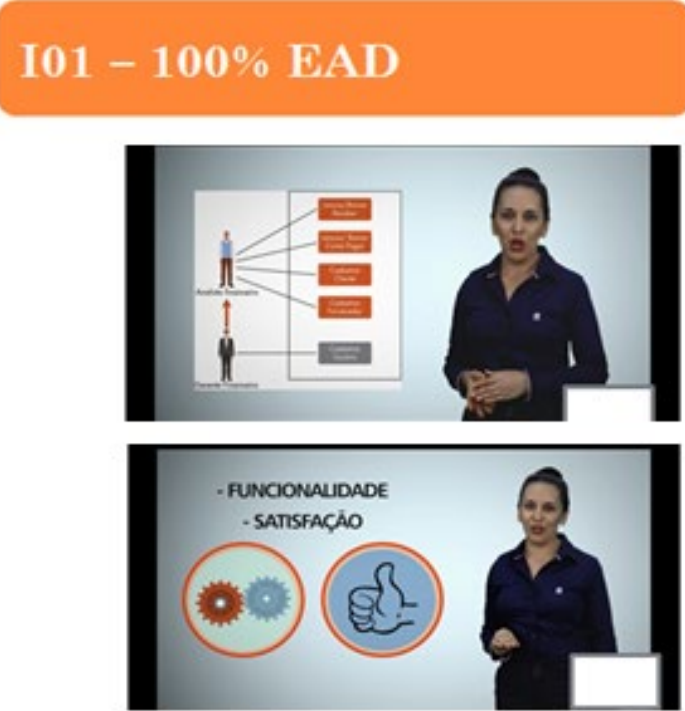

\section{I02 - EAD + PRESENCIAL}

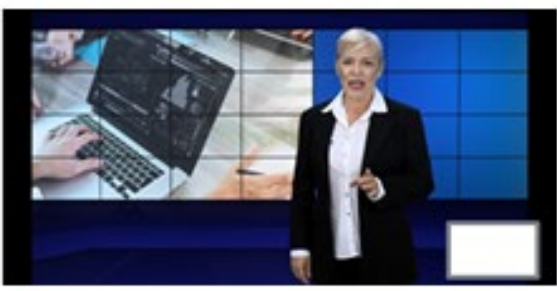

Fonte: Produzida pela autora (2019).

Como resultado temos dois modelos de videoaula diferentes, a primeira, da universidade i01, como se pode observar na figura 03, é mais jovial e utiliza bastante recursos gráficos para passar o conteúdo, é mais clean em seu design e a apresentação é baseada numa conversa com o aluno, a estrutura do texto narrado é montada em cima de cases da prática

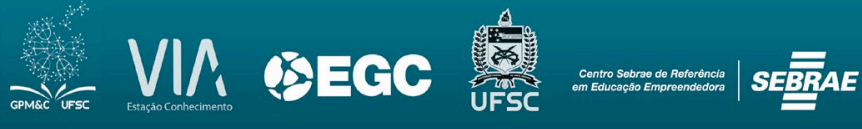




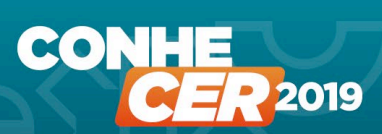

PONTES PARA FUTUROS

profissional, ponto central da videoaula, e que ilustram o cotidiano que o aluno irá vivenciar futuramente.

A outra videoaula proposta para atender as necessidades da i02 é mais tradicional, desde a figura do apresentador, que deve passar mais formalidade durante sua fala até a utilização de recursos, mais voltados para utilização de letterings e fotos. A estrutura textual tem o encaminhamento mais sério, o apresentador "simula" (apenas de forma figurativa) a postura de um professor e elenca os principais pontos teóricos vistos no e-book, trazendo alguns exemplos ou situações práticas.

Após esses protótipos diferentes montados, a produção foi escalonada de forma proporcional com o plano de ensino proposto para cada curso, visando abranger todas as disciplinas contratadas pelas instituições. Posteriormente, os produtos foram entregues às universidades demandantes e aprovados por suas respectivas comissões.

É importante colocar que, como quesito final de todo o processo de produção observado, a equipe envolvida verificou a existência de pontos que precisam ser observados a posteriori, inclusive estudados, que é a questão da aceitação por parte dos alunos de cada instituição das produções. Essa parte de investigação da eficiência e eficácia dos produtos diretamente no usuário extremo, que são os alunos, é uma próxima etapa que está para ser realizada pela empresa produtora dos protótipos. E, certamente, cabe espaço para outras reflexões posteriores.

\section{Reflexões conclusivas}

O processo descrito nesse relato pôde mostrar a versatilidade do método do Design thinking e como suas ferramentas podem ser uteis para montar protótipos. A escolha do vídeo para ser uma das mídias dos entregáveis de cada universidade se dá pelo "ser audiovisual" estatuto que as imagens ocupam e operam em escala importante, se estendendo ao ensino.

Hoje, cada vez mais, a linguagem audiovisual para EAD vem sido utilizada, isso tem elação com as formas de expressão que permitiriam o rápido aprendizado, visualização de informações e ideias, além de considerar que a maioria dos alunos já estaria familiarizada com esse universo "visual", principalmente com o advento das redes sociais e plataformas multimídias.

A intencionalidade e o processo de coautoria intencional, tanto na concepção quanto nas produções dos diversos profissionais, permitiu que o processo fosse visto de diversas formas e ângulos, o que remete a algo natural do Design Thinking: a colaboração e a co-criação entre os participantes do processo.

\section{$\Rightarrow$ VIA QEeC}


As ideias propostas aqui bem como o caminho percorrido pelos produtores podem servir como inspiração para geração de ideias e descrever processos criativos que podem ser utilizados nos produtos de outras instituições ou profissionais do setor.

\section{Referências}

BROWN, T. Design Thinking. Uma metodologia poderosa para decretar o fim das velhas ideias. Rio de Janeiro: Elsevier, 2010.

GOMBRICH, E. H. Os usos das imagens: estudo sobre a função social da arte e comunicação visual. Porto Alegre: Bookman, 2012.

LIEDTKA, J; OGILVIE, T. A magia do design thinking: um kit de ferramentas para o crescimento rápido da sua empresa. São Paulo: HSM, 2015.

LOGAN, R. K. Design Thinking, Strategic Foresight, Business Model Generation and Biology: A Mashup. Conference paper for use in workshops at MaRS and in the Think Tank course at OCAD University, 2012. Ontario College of Arts and Design University. Ontário - CN. Disponível em: https://www.researchgate.net/publication/267037971

MARTIN, R. The design of business: why designt hinking is the next competitive advantage. Boston: Harvard Business, 2019.

MELO, A.; ABELHEIRA, R. Design thinking \& thinking design: metodologia, ferramentas e uma reflexão sobre o tema. São Paulo: Novatec, 2015.

MENDONÇA, M. C. de et al. Design Thinking, Mídia, Conhecimento e Inovação: Reflexões sobre umaa_vidade didá_ca aplicando o Desenho da Persona e o Mapa Da Jornada Do Usuário. CIKI, 7.,11- 12 set. 2017, Foz do Iguaçu - PR. Anais...: Disponível em:hdp://proceeding.ciki.ufsc.br/index.php/ciki/ar_cle/view/170/60.

MOZOTA, B. B. DE; KLÖPSCH, C.; COSTA, F. C. X. da. Gestão do design: usando o design para construir valor de marca e inovação corporativa. Porto Alegre: Bookman, 2003.

SANTAELLA, L.; NÖTH, W. (Orgs.). Palavra e Imagem nas mídias: um estudo intercultural. Belém: EDUFPA, 2008.

ROSENBAUM, P. R. Design of observational studies. New York, NY: Springer-Verlag, 2010.

VIANNA, M. et al. Design thinking : inovação em negócios. Rio de Janeiro: MJV Press, 2012. Disponível em: hdp://livrodesignthinking.com.br/livro_dt_MJV.pdf 